\title{
Obtención de Etanol y Biogás a Partir de Banano de Rechazo
}

\author{
Carlos A. Guevara*, Héctor A. Arenas, Alexander Mejía y Carlos A. Peláez \\ Universidad de Antioquia, Grupo Interdisciplinario de Estudios Moleculares (GIEM), \\ Inst. De Química, Calle 67 Nº 53-108, Medellín-Colombia. (e-mail: carlosguevara@utp.edu.co ) \\ * Autor a quien debe ser dirigida la correspondencia.
}

Recibido Ago. 25, 2011; Aceptado Oct. 12, 2011; Versión Final recibida Nov. 03, 2011

\begin{abstract}
Resumen
Se desarrolló un proceso fermentativo mediante hidrólisis endógena inducida para producir etanol a partir de banano verde no apto para exportación. El potencial de las vinazas también fue evaluado para obtener biogás. A escala de 1 litro se comparó la hidrólisis endógena inducida con la hidrólisis exógena usando enzimas comerciales, y la hidrólisis ácida tomando como punto de referencia el etanol producido en la fermentación. Con la hidrólisis endógena se obtuvo los mayores rendimientos y con esta metodología se realizaron fermentaciones a 15 litros Los rendimientos de etanol en promedio fueron 0.065 litros por kilogramo de banano verde y los del biogás fueron 2.24 litros por litro de vinaza. El proceso propuesto presenta rendimientos comparables con los de la fermentación de caña de azúcar. Además presenta ventajas, tales como su bajo costo, fácil operación y por ser una alternativa de solución ambientalmente compatible en el área del manejo de residuos de cosecha.
\end{abstract}

\section{Biogas and Bioethanol Production from Non-Exportable Low Quality Banana}

\begin{abstract}
In this study was developed a fermentative process to produce ethanol from green banana non optimal for exportation through one induced endogenous hydrolysis. The potential of the stillage to produce biogas was also evaluated. It was compared the induced endogenous hydrolysis, with the exogenous hydrolysis that uses commercial enzymes and the traditional acid hydrolysis done all of them in a final volume of 1 liter, the reference point was the ethanol produced in the fermentation process. The maximum performance was obtained with the endogenous hydrolysis and with these methodology fermentations at 15 liter as done. The average of ethanol produced was 0.065 liters from one kilogram of green banana and the biogas production was 2.24 liter per liter of stillage. The proposed process shows performance comparable with that obtained by sugar cane fermentation. Also the methodology demonstrated several advantages, such as low cost, simple to operate, and because it constitutes a good alternative, which is environmentally compatible in the area of management of crop residues.
\end{abstract}

Keywords: enzymatic hydrolysis, rejected banana, ethanol, biogas, fermentation 


\section{INTRODUCCION}

La industria bananera de exportación en Colombia genera una importante cantidad de biomasa residual denominada banano de rechazo, que tiene tres características importantes: 1) no se exporta, 2) está concentrada en las empacadoras de fruta, 3) representa un volumen importante. Estas condiciones hacen que este sustrato sea atractivo para emprender un estudio que permita evaluar su uso como materia prima en la producción de biocombustibles, teniendo en cuenta que el esfuerzo energético por concentrar la fruta se hizo con fines de exportación, lo que reduce significativamente su costo energético como materia prima y con ello también se reduzca ostensiblemente su huella de carbono. El banano para exportación se cosecha verde, se transporta hasta las empacadoras donde mediante criterios de tamaño y apariencia se selecciona en dos categorías básicas: Fruta de exportación y fruta de rechazo. Las cifras de banano verde de rechazo, oscilan entre 6.5 y $10.8 \mathrm{t} / \mathrm{año} / \mathrm{ha}$, por tanto el volumen total en Colombia es de unas 400.000 t/año (Sierra, 2007). En el caso específico de la zona de Urabá -noroccidente del país- al año se cuenta con unas 250.000 t de banano de rechazo (Augura, 2007).

Actualmente una tercera parte de la fruta que no se exporta se destina al consumo interno como fruta fresca, otra tercera parte se emplea como sustrato en la producción de fertilizantes orgánicos (compost) para el cultivo de la misma fruta y, una tercera parte continúa considerándose como residuo. Son precisamente estas últimas $2 / 3$ partes del residuo las que potencialmente se pueden usar en la producción de biocombustibles.

Durante años, esta biomasa se constituyó en una de las problemáticas ambientales más importantes de las zonas bananeras y en un intento de solución, en 1987 el CIID (Centro Internacional de Investigaciones y el Desarrollo) de Canadá donó un sistema de producción de alcohol con el que se estimó la viabilidad del uso de estos residuos para la obtención de etanol, por medio de un proceso hidrolítico/fermentativo seguido de una destilación. El costo de la hidrólisis ácida (Canché-Escamilla et al, 2005), comparado con el valor para la época de los combustibles fósiles, hicieron que esta iniciativa fuera considerada como inviable. Sin embargo, una alternativa no estudiada a fondo en su momento fue la conversión de carbohidratos a través de una hidrólisis enzimática endógena inducida, y más aún si se consideran los costos actuales del petróleo (Augura y Fábrica de Licores de Antioquia, 1990). En un trabajo realizado en la Universidad de Texas A\&M, se estudiaron el potencial de los bananos de rechazo para la producción de etanol en diferentes estados de maduración, obteniendo para banano verde 0.090, maduro 0.082, sobre madurado $0.069 \mathrm{~L}$ etanol $/ \mathrm{Kg}$ de toda la fruta (Hammond et al., 1996)

Posteriores esfuerzos se han realizado en todos los frentes de investigación y muchas de estas experiencias se encuentran debidamente documentadas en la revisión bibliográfica: "El banano verde de Rechazo en la Producción de Alcohol Carburante" (Afanador, 2005), en donde se abordan aspectos tales como, la disponibilidad del material, tipos de hidrólisis, fermentaciones con diferentes tipos de microorganismos, separación y deshidratación del etanol (Beckley et al, 2005). También se efectuó un análisis energético y exergético para evaluar el proceso de obtención de etanol a partir de banano; analizando el cultivo y transporte del material, hidrólisis del banano, fermentación de los azúcares, destilación del etanol y planta de utilidades. Finalmente se demostró que el balance energético es positivo pero debe mejorarse (Velásquez et al., 2009).

A veinte años de la primera experiencia, es posible pensar en obtener etanol a partir de este tipo de residuos agroindustriales, con dos aspectos claros para considerar: 1) Mejorar el rendimiento, bajar el costo de la hidrólisis y desarrollar una metodología adecuada de extracción de los azúcares fermentables. 2) Disminuir el costo energético de la producción de etanol mediante la obtención simultanea otros biocombustibles y coproductos a partir de los residuos hasta llegar a implementar el concepto de biorrefineria (Rabelo et al., 2011).

En éste estudio se pretendió abordar la problemática desde una visión holística. Considerando todas las etapas del proceso a dos escalas diferentes. Fueron realizadas 5 etapas: hidrólisis, extracción y neutralización de jugos (Lee et al., 2006; Kyamuhangire et al., 2002; Kyamuhangire Et al., 1999), la evaluación fisicoquímica del jugo, fermentación etanólica, destilación y finalmente producción de biogás a partir de las vinazas, con el fin de obtener biocombustibles a partir de banano de rechazo. 


\section{METODOLOGÍA}

\section{Métodos analíticos}

Bajo la Norma Técnica Colombiana (NTC) fueron cuantificados Nitrógeno (NTC 370), Fosforo (NTC 234). La capacidad de retención de agua (CRA), humedad, pH, carbono orgánico, cenizas y densidad se determinaron según la norma (NTC 5167). Los azúcares reductores fueron cuantificados por un método espectrofotométrico, utilizando DNS (ácido 3,5-dinitrosalicílico) y adicionalmente los azucares solubles por refractometría, técnica usalmente denominada Grados Brix ( $\left.{ }^{\circ} \mathrm{Bx}\right)$. Potasio, Sodio, Calcio, Magnesio, Zinc, Aluminio se cuantificaron por Electroforesis capilar. Azufre por gravimetría bajo la norma AOAC 98002 (Association of Oficial Analytical Chemists), Conductividad y $\mathrm{pH}$ bajo norma SSLMM-42-2-92: Soil Survey Laboratory Methods Manual Reporte $N^{\circ} 42$, Versión 2.0, 1992. Sólidos totales por gravimetría bajo norma APHA (American Public Health Association), AWWA (American Water Works Association) y WPCF (Water Pollution Control Federation). La caracterización enzimática, tanto cinética como de punto final, fue estimada por determinación de las velocidades iniciales según los protocolos definidos para valoraciones en heterofase (Peláez et al., 2004). La concentración alcohólica fue estimada por cromatografía de gases, usando un equipo Marca Agilent 6890 con detector FID, dotado de una columna Carbowax $20 \mathrm{M}$ de $50 \mathrm{~m}$ de longitud y $1 \mu \mathrm{m}$ de diámetro interno; el volumen de inyección fue de $1 \mu \mathrm{L}$ y una división de 1:50. La Temperatura del inyector fue de $200{ }^{\circ} \mathrm{C}$ y el flujo de gas portador de $20 \mathrm{~mL} / \mathrm{min}$ de $\mathrm{H}_{2}$ (O'Neal, et al 1996). El contenido de biogás fue establecido por volumetría y prueba de llama.

\section{Hidrólisis y extracción}

Los bananos verdes fueron adquiridos en la central de alimentos minorista de Medellín y transportados inmediatamente al laboratorio. Tres procedimientos fueron empleados en la hidrólisis y extracción de los jugos: En la hidrólisis endógena, una cámara de maduración equipada con sistema de humidificación, calentamiento y medidores de temperatura y humedad, fue usada para la hidrólisis por inducción de enzimas endógenos. Para la inducción, la concentración de etileno en la cámara fue de $50 \mathrm{ppm}$, la temperatura de $25^{\circ} \mathrm{C}$ y la humedad relativa de $85 \%$ todo esto se mantuvo por 96 horas, según una estandarización cinética realizada previamente (Paull, 2000; Margossian et al 1988). La extracción de los jugos se realizó en una etapa por adición de $300 \mathrm{~mL}$ de solución acuosa de $\mathrm{Ca}(\mathrm{OH})_{2}$ al $10 \%$ por cada $\mathrm{Kg}$ de banano, mezclado y dejado en reposo por 15 minutos y luego centrifugación. Posteriormente el jugo fue neutralizado con $\mathrm{H}_{2} \mathrm{SO}_{4}$ comercial, pasteurizado y nuevamente filtrado hasta obtener el jugo clarificado. En la hidrólisis por enzimas exógenas se tomaron $80 \mathrm{~g}$ de banano verde que se maceraron con $250 \mathrm{~mL}$ de buffer acetato $0.05 \mathrm{M}$ y pH 5.0. El material resultante se sometió a 2 atm y $121^{\circ} \mathrm{C}$ por 1 hora en autoclave (All American model $N^{\circ} 25$ ). El jugo pre tratado se llevó a $55^{\circ} \mathrm{C}$ en baño maría, se sometió a agitación mecánica, y se le agregaron $0.250 \mathrm{~mL}$ de cada uno de los enzimas amilolíticos (Termamyl 120L y Amylase AG 300L), se dejó transcurrir la hidrólisis por espacio de 3 horas y finalmente se filtró. Este jugo clarificado fue utilizado para la fermentación. En la hidrólisis química se empleó el mismo equipo empleado en el pre tratamiento anterior a las mismas condiciones de volumen, presión y temperatura con ácido sulfúrico al $0.5 \%$ y durante 30 minutos (Baret, 2003). El jugo fue entonces neutralizado a $\mathrm{pH} 5.5$, filtrado y utilizado para la fermentación. Todos los ensayos fueron realizados por triplicado. El ensayo con mejores contenidos de alcohol fue repetido a una escala superior en un reactor con capacidad nominal de $20 \mathrm{~L}$ hasta completar un total de 15 repeticiones.

\section{Fermentaciones}

Las fermentaciones se llevaron a cabo en dos niveles dependiendo del tamaño del fermentador. En el primer nivel se utilizó un fermentador de $1 \mathrm{~L}$ equipado con sistema de agitación mecánico y fue útil para comparar las metodologías de hidrólisis y extracción de jugos. Los ensayos fueron realizados por triplicado. 
En el nivel II se utilizó un fermentador de capacidad $20 \mathrm{~L}$ equipado con sistema de agitación hidráulica.

El microorganismo empleado para la fermentación fue la levadura Saccharomyces cerevisiae (Mauripan $\AA$ ), activada en agua a $37^{\circ} \mathrm{C}$ durante 30 minutos. Las fermentaciones se realizaron a temperatura ambiente $\left(25^{\circ} \mathrm{C}\right)$ y por un periodo de 48 horas. El etanol presente en el fermento fue cuantificado por cromatografía de gases. Los fermentos fueron destilados a presión atmosférica. Las condiciones a las que fueron realizadas las fermentaciones en los niveles I y II son presentadas en la tabla 1.

Tabla 1. Parámetros fisicoquímicos y microbiológicos para fermentaciones en nivel I y II

\begin{tabular}{|l|l|}
\hline Parámetro & Nivel I y II \\
\hline Microorganismo & Saccharomyces cerevisiae \\
\hline Concentración inicial de levadura & $1.0 \times 10^{9}-7,0 \times 10^{8}$ células $/ \mathrm{mL}$ \\
\hline Viabilidad inicial & $98-100 \%$ \\
\hline Viabilidad final & $97 \%$ \\
\hline Capacidad Max. del Reactor & 1.0 L para el nivel I y 20.0 L para el nivel II \\
\hline Agitación & Hidráulica (I) y mecánica (II) \\
\hline Tiempo de fermentación & 48 horas \\
\hline pH inicial & 5.6 \\
\hline Temperatura del proceso & $25 \pm 3^{\circ} \mathrm{C}$ \\
\hline
\end{tabular}

\section{Producción de biogás}

Las vinazas resultantes de la destilación del alcohol fueron analizadas y sometidas a digestión anaerobia en un reactor discontinuo con capacidad de $5.0 \mathrm{~L}$. La producción de biogás fue realizada con y sin inoculo. Cuando se utilizó inoculo, se empleo a una concentración del $10 \%$ en peso de porquinaza (excretas de cerdo) o rumen, con respecto a los sólidos totales en la vinaza. El proceso se realizó con y sin control de $\mathrm{pH}$. Los ensayos fueron realizados por triplicado. El biogas producido se hizo pasar por dos trampas (para ácido sulfhídrico y $\mathrm{CO}_{2}$ y posteriormente se le realizó prueba de ignición.

\section{RESULTADOS Y DISCUSION}

Las características fisicoquímicas más importantes de la materia prima (fruta verde), se aprecian en la tabla 2.

Del análisis de la tabla 2 se deduce que la fruta de banano se caracteriza por poseer alta humedad y un significativo contenido de materia orgánica representado por una importante cantidad de almidón (Aurorea, 2009; Prabha and Bhagyalakshmi, 1998). Hay poca presencia de azúcares fermentables tal y como lo demuestran los análisis de ${ }^{\circ} \mathrm{Bx}$ y los azúcares reductores. Adicionalmente el bajo contenido de nitrógeno indica una baja presencia de proteína. 
Tabla 2. Propiedades fisicoquímicas del banano verde. * Capacidad de Retención de Agua. ** miliMolar.

\begin{tabular}{|c|c|c|c|c|}
\hline Parámetro & Expresado como & Método & Norma & Valores \\
\hline Nitrógeno & $\mathrm{N}$ total & Kjeldahl & NTC 370 & $0.19 \%$ \\
\hline Fósforo & $\mathrm{P}_{2} \mathrm{O}_{5}$ & Espectrofotométrico & NTC 234 & ND \\
\hline $\mathrm{CRA}^{*}$ & CRA & Volumétrico & NTC 5167 & $197.03 \%$ \\
\hline Humedad & Humedad & Gravimétrico & NTC 5167 & $80.9 \%$ \\
\hline $\mathrm{pH}$ & $\mathrm{pH}$ & Potencio métrico & NTC 5167 & 5.94 \\
\hline Carbono Orgánico & C.O & Volumétrico & NTC 5167 & $38.8 \%$ \\
\hline Cenizas & Cenizas & Gravimétrico & NTC 5167 & $0.6 \%$ \\
\hline Densidad & Densidad & Gravimétrico & NTC 5167 & $0.6 \mathrm{~g} / \mathrm{cc}$ \\
\hline \multirow{2}{*}{ Azúcares } & ${ }^{\circ}$ Brix & Refracto métrico & \multirow{2}{*}{ No aplica } & 1.5 Brix \\
\hline & Azúcares reductores & Espectrofotométrico & & $8.0 \mathrm{mM}^{* *}$ \\
\hline
\end{tabular}

La hidrólisis del almidón presente en el banano debe ser considerado como el paso clave para la producción de etanol. En éste paso ocurre la conversión de amilosa y amilopectina a azúcares fermentables que posteriormente pueden ser convertidos a etanol por levaduras y bacterias (Mojovic et al, 2006)

La figura 1 muestra los resultados que se obtienen al evaluar los diferentes procesos de hidrólisis con respecto a los sólidos solubles $\left({ }^{\circ} \mathrm{Bx}\right)$ y el etanol producido. Si se considera una concentración de carbohidratos en el banano completo, cercana al 29\% (Aurorea, 2009). En términos de los ${ }^{\circ} \mathrm{Bx}$ la hidrólisis ácida ofrece aproximadamente un $95 \%$ de conversión de los carbohidratos, mientras que la hidrólisis endogena alcanza un $60 \%$ y la exogena un $45 \%$. En principio y a partir del referente de la refractometría, dos de los procesos pueden ser tenidos en cuenta para un segundo nivel de análisis: La hidrólisis ácida y la hidrólisis enzimática endógena.

Dado que no adecuado tener como único criterio de decisión el poder hidrolítico, esto se complementó con la capacidad de convertir el producto hidrolizado en alcohol, evaluándose mediante cromatografía de gases, para así definir el protocolo más adecuado. En este sentido, los rendimientos de la hidrólisis ácida son bajos, dado que no superan el $4 \%$ de alcohol, hecho que no se compadece con lo esperado según los ${ }^{\circ} \mathrm{Bx}$ alcanzados en la hidrólisis. Esto se atribuye a la degradación de los azúcares fermentables hasta llegar a furfural durante la hidrólisis (Davis. L., et al 2005; Nigam J. N., 2001). Esto contrasta significativamente con lo que se presenta en el caso de la hidrólisis endógena donde se obtienen valores de alcohol que en promedio se acercan al $7.0 \%(\mathrm{~V} / \mathrm{V})$.

En ésta primera etapa cabe anotar que si todos los carbohidratos presentes en el banano fueran convertidos a azúcares fermentables y estos posteriormente a etanol con la mayor eficiencia, se deberían obtener aproximadamente $0.170 \mathrm{~L}$ de etanol por cada $\mathrm{kg}$ de banano. Esto sin tener en cuenta que parte de la celulosa (hemicelulosa) está conformada por varios tipos de pentosas que no son susceptibles de degradar por la levadura Saccharomyces cerevisiae que fue utilizada para éste estudio. 


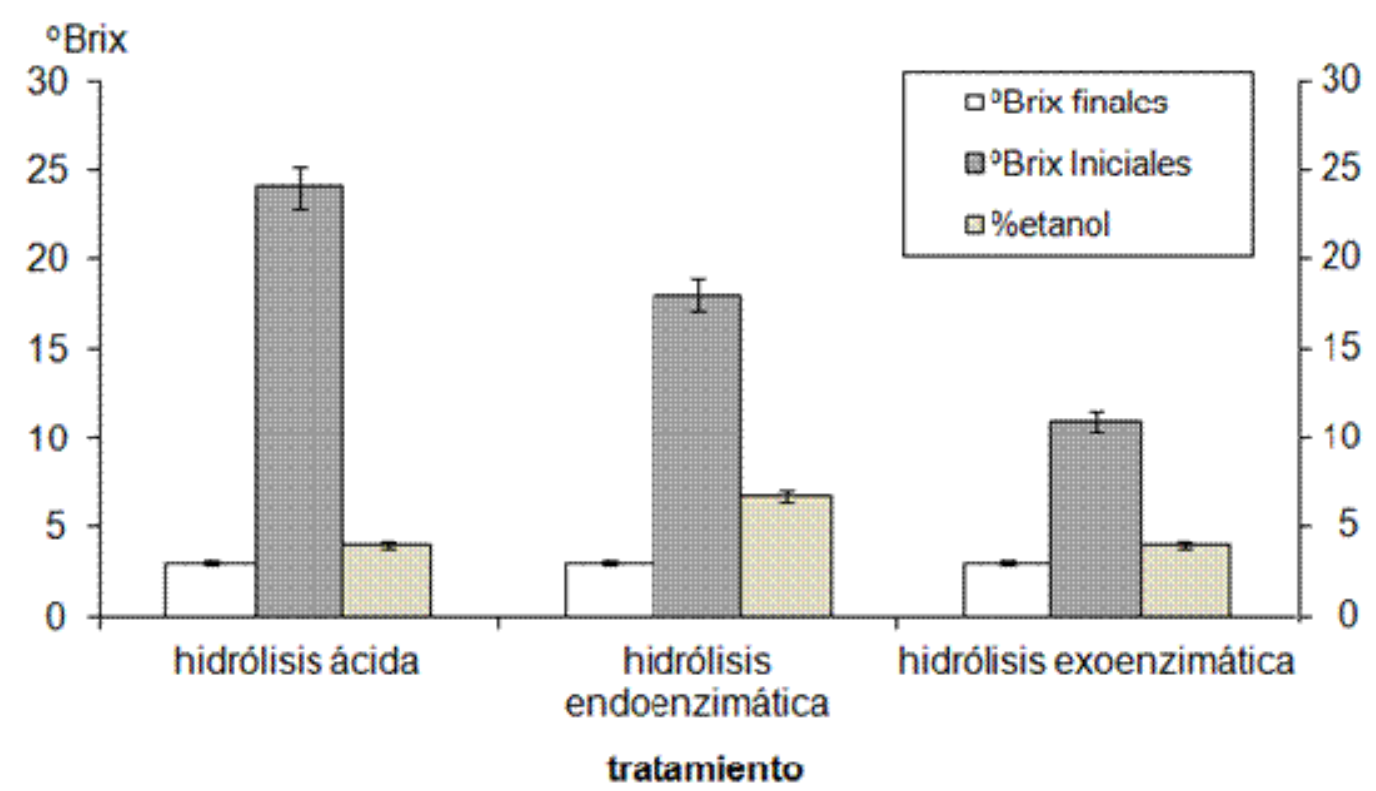

Fig 1: Efecto del tipo de hidrólisis sobre los ${ }^{\circ}$ Brix y la concentración final de etanol

Tomando como base estos resultados en la figura 1, se optó por continuar los experimentos con un jugo formulado a partir de hidrólisis con enzimas endógenos y posterior extracción con lechada de cal $\left(\mathrm{Ca}(\mathrm{OH})_{2}\right)$. No solo por el contenido de alcohol en el fermento, sino por viabilidad técnica y económica ya que no es necesario comprar enzimas o equipos que trabajen a altas temperaturas. Para realizar el escalado a volúmenes de $20 \mathrm{~L}$, se realizó la hidrólisis por inducción con enzimas endógenas en una cámara de maduración. El jugo fue obtenido siguiendo el protocolo previamente al nivel de $1 \mathrm{~L}$ y guardando las proporciones. Las propiedades fisicoquímicas del jugo producido a partir del banano hidrolizado por los enzimas endógenos y extraído con lechada de cal, se presentan en la tabla 3. Cabe destacar la baja concentración de Nitrógeno y Fosforo y la alta concentración de Azufre y Calcio en el jugo, debida principalmente a la adición de $\mathrm{Ca}(\mathrm{OH})_{2}$ en el proceso de extracción y posterior neutralización con $\mathrm{H}_{2} \mathrm{SO}_{4}$. La cantidad de sólidos solubles (15.5 $\mathrm{Bx}$ ) en el jugo, fue considerada adecuada porque una fermentación óptima produciría concentraciones de alcohol cercanas al 9.0\% (V/V) en el fermento e impidiendo la inhibición por sustrato.

Para las 15 fermentaciones más representativas a volúmenes de $15 \mathrm{~L}$, se obtuvieron los resultados que se presentan en la tabla 4.

Al correlacionar las diferentes variables estudiadas, se obtienen los valores que se presentan en la matriz de correlación que corresponde a la figura 2. De aquí se desprende dos hechos a destacar: 1) En la correlación de las variables ${ }^{\circ} B x$ y \%Alcohol, para valores altos en ${ }^{\circ} B x$ se pierde la linealidad. Esto implica que la producción de alcohol no es de dependencia única del nivel de azúcares presentes en el jugo y que existen otras variables como por ejemplo vitalidad celular, que juegan un papel determinante en la optimización de los procesos de fermentación (RodríguezPorrata et al., 2008). 2) El comportamiento asintótico en la producción del jugo a partir de la fruta disponible, se interpreta como una tendencia a la saturación en la capacidad extractante del solvente, lo que tiene trascendencia en la estimación del rendimiento máximo. Una forma más expedita de visualizar estos hechos se da mediante la formulación de las variables derivadas, tal y como se indica en la tabla 5. 
Tabla 3: Propiedades fisicoquímicas del jugo de banano. * Electroforesis capilar ** Método desarrollado por el GIEM.

\begin{tabular}{|c|c|c|c|c|c|}
\hline Parámetro & $\begin{array}{c}\text { Expresado } \\
\text { como }\end{array}$ & Método & Norma & $\begin{array}{c}\text { Resultados } \\
\pm \text { de }\end{array}$ & Unidades \\
\hline Nitrógeno & $\mathrm{N}$ total & Kjeldahl & NTC 370 & $0.52 \pm 0.10$ & $g / L$ \\
\hline Fosforo & $\mathrm{P}_{2} \mathrm{O}_{5}$ & Fotométrico & NTC 234 & N.D & $g / L$ \\
\hline Potasio & $\mathrm{K}_{2} \mathrm{O}$ & E.C. ${ }^{*}$ & No aplica** & $8.34 \pm 0.41$ & $g / L$ \\
\hline Sodio & $\mathrm{Na}$ & E.C.* & No aplica** & N.D & $g / L$ \\
\hline Calcio & $\mathrm{CaO}$ & E.C. ${ }^{*}$ & No aplica** & $7.54 \pm 0.25$ & $g / L$ \\
\hline Magnesio & $\mathrm{MgO}$ & E.C. ${ }^{*}$ & No aplica** & N.D & $\mathrm{g} / \mathrm{L}$ \\
\hline Zinc & $\mathrm{Zn}$ & E.C. ${ }^{*}$ & No aplica** & N.D & $g / L$ \\
\hline Aluminio & $\mathrm{Al}$ & E.C. ${ }^{*}$ & No aplica** & N.D & $\mathrm{g} / \mathrm{L}$ \\
\hline Carbono org. & C.O & Volumétrico & NTC 5167 & $80.64 \pm 3.67$ & $g / L$ \\
\hline Azufre & $S$ & Gravimétrico & AOAC 98002 & $2.12 \pm 0.16$ & $g / L$ \\
\hline Relación C/N & No aplica & No aplica & No aplica & 153.60 & - \\
\hline $\mathrm{pH}$ & $\mathrm{pH}$ & $\begin{array}{l}\text { Potencio } \\
\text { métrico }\end{array}$ & SSLMM-42-2-92 & $5.64 \pm 0.00$ & - \\
\hline Conductividad & Conductiv & $\begin{array}{l}\text { Potencio } \\
\text { métrico }\end{array}$ & SSLMM-42-2-92 & $8.17 \pm 0.02$ & $\mathrm{mS} / \mathrm{cm}$ \\
\hline Densidad & Densidad & Gravimétrico & NTC 5167 & $1.05 \pm 0.01$ & $\mathrm{~g} / \mathrm{mL}$ \\
\hline $\begin{array}{l}\text { Sólidos } \\
\text { totales }\end{array}$ & No aplica & Gravimétrico & $\begin{array}{c}\text { APHA-AWWA WPCF } \\
2540 B\end{array}$ & $163.4 \pm 0.98$ & $g / L$ \\
\hline Azúcares & ${ }^{\circ}$ Brix & $\begin{array}{l}\text { Refracto } \\
\text { métrico }\end{array}$ & No aplica & 15.5 & $\begin{array}{c}{ }^{\circ} \text { Brix } \\
\text { g/100mL }\end{array}$ \\
\hline
\end{tabular}

Tabla 4: Parámetros estadísticos de las fermentaciones

\begin{tabular}{|l|c|c|c|c|}
\hline Parámetro & $\begin{array}{c}\text { Banano } \\
(\mathrm{Kg})\end{array}$ & $\begin{array}{c}\text { Jugo } \\
(\mathrm{L})\end{array}$ & ${ }^{\circ} \mathrm{Bx}$ & $\begin{array}{c}\text { Alcohol en } \\
\text { vino } \\
\%(\mathrm{v} / \mathrm{v})\end{array}$ \\
\hline $\mathrm{N}^{\circ}$ de Ensayos & 15 & 15 & 15 & 15 \\
\hline Promedio & 15.1 & 13.8 & 12.4 & 6.7 \\
\hline Desviación Estándar & 5.1 & 5.5 & 4.1 & 2.3 \\
\hline Coeficiente variación & $33.9 \%$ & $40.1 \%$ & $33.5 \%$ & $34.3 \%$ \\
\hline Valor Mínimo & 4.25 & 4.5 & 4.0 & 1.7 \\
\hline Valor Máximo & 20.3 & 22.0 & 16.0 & 10.3 \\
\hline Intervalo & 16.05 & 17.5 & 12.0 & 8.6 \\
\hline
\end{tabular}




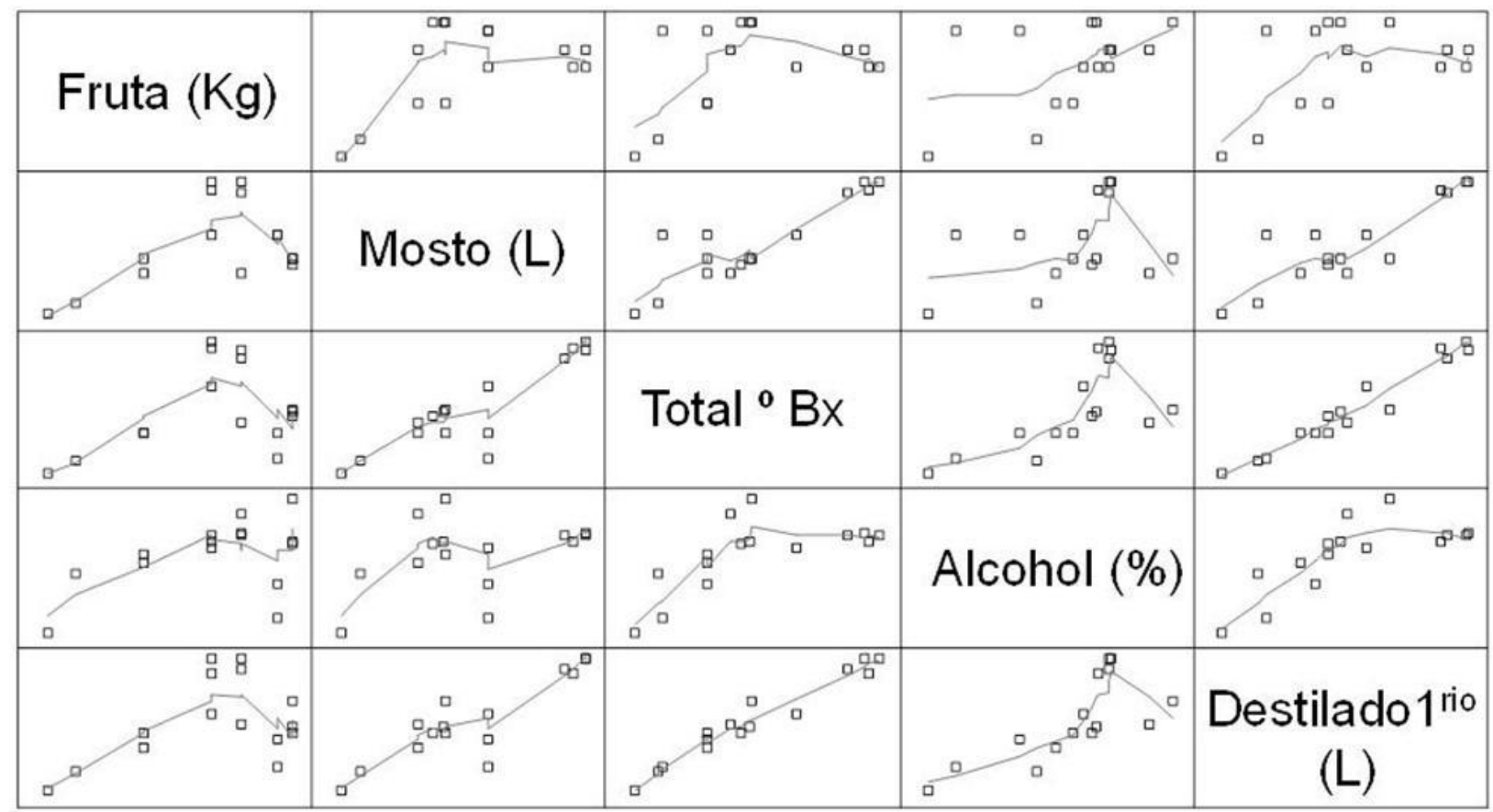

Fig. 2: Correlaciones entre variables básicas en fermentaciones de jugos

Tabla 5. Rendimientos y parámetros estadísticos de la producción de alcohol a partir de banano de rechazo.

\begin{tabular}{|l|c|c|c|c|}
\hline $\begin{array}{l}\text { Parámetro } \\
\text { Estadístico }\end{array}$ & $\begin{array}{c}\text { Jugo }(\mathrm{L}) / \\
\text { Banano }(\mathrm{Kg})\end{array}$ & $\begin{array}{c}\text { Alcohol }(\mathrm{L}) / \\
\text { Banano }(\mathrm{Kg})\end{array}$ & $\begin{array}{c}\text { Alcohol }(\mathrm{g}) / \\
\text { Vino }(\mathrm{L})\end{array}$ & $\begin{array}{c}\text { Alcohol }(\mathrm{g}) / \\
\text { Banano(g) }\end{array}$ \\
\hline Numero de Ensayos & 15 & 15 & 15 & 15 \\
\hline Promedio & 0.96 & 0.065 & 53.3 & 0.051 \\
\hline Desviación Estándar & 0.31 & 0.031 & 18.3 & 0.025 \\
\hline Coef. Variación & $32 \%$ & $48.6 \%$ & $34 \%$ & $48.6 \%$ \\
\hline Mínimo & 0.54 & 0.018 & 13.4 & 0.014 \\
\hline Máximo & 1.47 & 0.118 & 81.4 & 0.093 \\
\hline Intervalo & 0.93 & 0.1 & 68 & 0.079 \\
\hline
\end{tabular}

De la tabla 5 se tiene que por cada kilogramo de fruta se formula en promedio 0.96 litros de jugo y que por cada litro de jugo se obtienen en promedio $53.3 \mathrm{~g}$ de alcohol; lo que en principio se puede considerar un rendimiento significativo. Sin embargo, debe tenerse en cuenta que la producción de etanol es función de la presencia de azúcares fermentables y que estos a su vez se relacionan con los ${ }^{\circ} \mathrm{Bx}$.

El valor máximo de alcohol obtenido en la fermentación fue de $0.12 \mathrm{~L}$ de alcohol/ $\mathrm{Kg}$ de banano lo que no está lejano del 0.17 propuesto como máximo teórico dado que representa el $70 \%$. Si bien es difícil pensar en superar este máximo experimental obtenido, si se tiene en cuenta que la hidrólisis endógena afecta principalmente al material amiláceo y no al celulósico presente en la cáscara, se requiere trabajar en mejorar el valor promedio $(0.065 \mathrm{~L}$ de etanol / $\mathrm{Kg}$ de fruta) dado que este valor solo representa el $40 \%$ del valor estequiométrico. Además debe tenerse en cuenta que la extracción de los azúcares fermentables es susceptible de mejorar.

En la figura 3 se evidencia que dadas las condiciones de la fruta se pueden obtener jugos de muy diferente concentración de azúcares, lo que se traduce en sistemas de alta, media y baja productividad de alcohol. La alta productividad está representada por fermentaciones que en promedio obtienen $0.11(\mathrm{~L})$ de alcohol por cada kilogramo de fruta, siempre y cuando el jugo en 
promedio posea $15.5^{\circ} \mathrm{Bx}$. Un hecho significativo que también está relacionado con la figura 3 es que el alto contenido de azúcares fermentables no es garantía de una buena fermentación. Este hecho es actualmente objeto de estudio para tratar de establecer las razones por las cuales a pesar de poseer un adecuado nivel de azúcares fermentables y condiciones óptimas de fermentación tales como agitación, $\mathrm{pH}$, temperatura, población de levaduras y viabilidad, en algunos casos se obtienen rendimientos significativamente menores de alcohol.

Cabe recordar que la cantidad de etanol obtenido a partir de caña de azúcar es de $0.086 \mathrm{~L}$ de etanol por Kg de caña de azúcar (BNDES y CGEE, 2008), por lo tanto los rendimientos obtenidos en el caso del banano son muy promisorios.

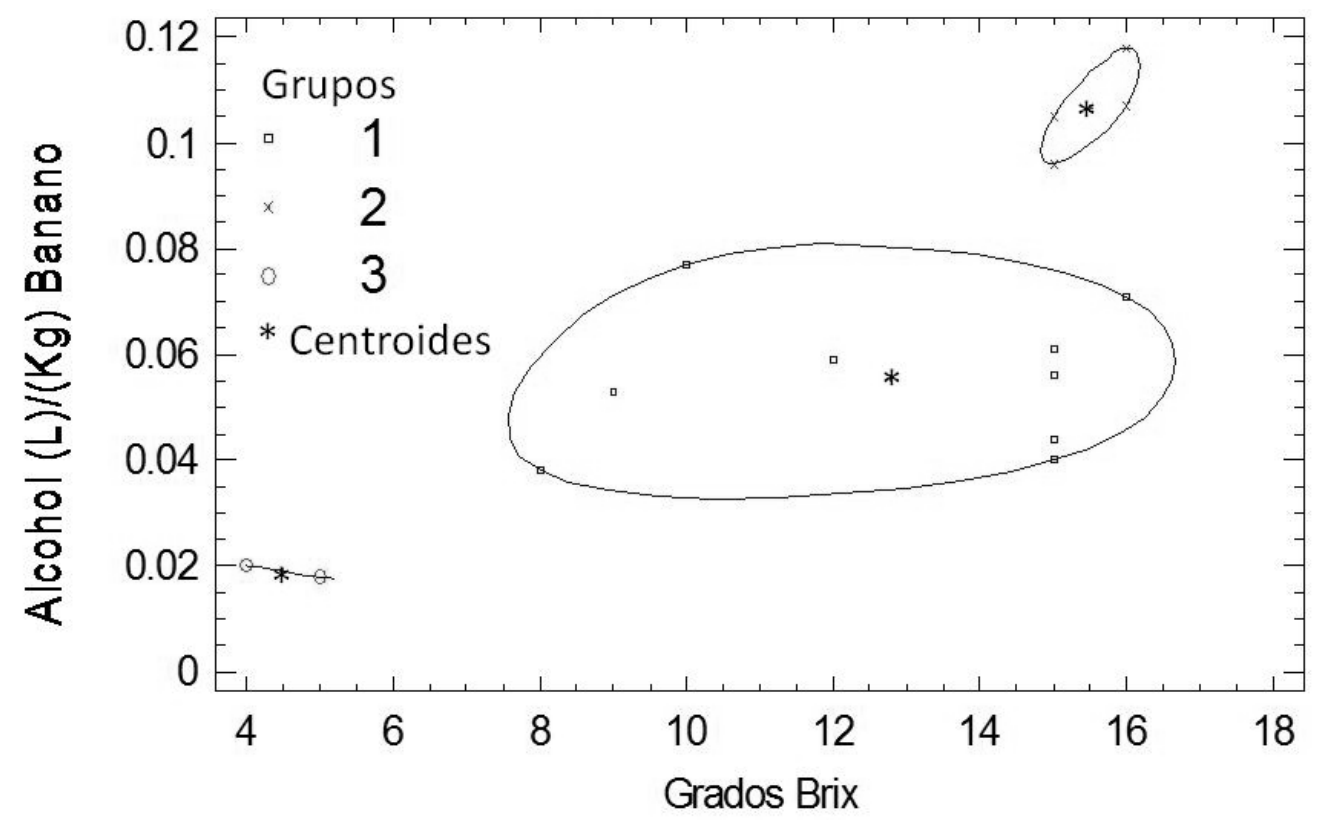

Fig 3: Análisis de clúster para las relaciones entre ${ }^{\circ}$ Brix y \% etanol en las fermentaciones

Las vinazas producidas durante la destilación del fermento estuvieron en una proporción de 12 a $14 \mathrm{~L}$ de vinaza por Litro de alcohol producido. Este volumen de vinaza es muy parecido al obtenido cuando se emplea jugo de caña para la formulación del mosto (BNDES y CGEE, 2008).

Para la producción de biogás, se procedió a determinar la composición de la vinaza de banano y además compararla con la de caña de azúcar cuando se emplea miel en la formulación del jugo. En la tabla 6 se muestran parámetros fisicoquímicos de ambas vinazas.

Tabla 6. Análisis fisicoquímico de vinazas de caña y banano. ST: sólidos totales; CO: carbono orgánico

\begin{tabular}{|c|c|c|c|c|c|c|}
\hline & $\mathrm{pH}$ & $\% \mathrm{ST}$ & $\% \mathrm{CO}$ & $\% \mathrm{~N}$ & $\% \mathrm{P}$ & $\% \mathrm{~K}$ \\
\hline Caña & 4.07 & 16.82 & 4.85 & 0.45 & 0.080 & 2.61 \\
\hline Banano & 4.15 & 2.70 & 1.14 & 0.07 & 0.006 & 1.12 \\
\hline
\end{tabular}

De acuerdo a la tabla 6 , la concentración de carbono orgánico es cuatro veces más alta en la vinaza de caña, obtenida de jugos formulados con miel que la correspondiente al banano, por lo tanto se esperará menor producción de biogás en ésta última. Además el \% de Nitrógeno también es mucho mayor en la vinaza de caña. La producción de biogás a partir de vinaza de banano es 
presentada en la tabla 7. Donde se pueden observar los rendimientos dependiendo de la naturaleza del inoculo y además los comportamientos cinéticos. Los porcentajes corresponden al aumento de la eficiencia respecto al ensayo sin inoculo. Cuando el reactor fue inoculado con porquinaza y rumen, los rendimientos aumentaron en $115 \%$ y $125 \%$ respectivamente. Igualmente la velocidad aumento en un 15 y $20 \%$. Debe reconocerse la importancia del inoculo en éste proceso, que permitió aumentar la velocidad y los rendimientos. Cabe anotar que el control de pH no tuvo mayor efecto sobre los resultados finales.

Tabla 7. Efecto del inoculo sobre la producción de biogás a partir de vinazas de banano

\begin{tabular}{|l|c|c|c|}
\hline Variable & Sin inoculo & Porquinaza & Rumen \\
\hline Rendimiento $(L$ de biogás $/ L$ de sustrato) & $0.92 \pm 0.05$ & $2.09 \pm 0.13$ & $2.24 \pm 0.13$ \\
\hline Velocidad de producción $(\mathrm{mL} / \mathrm{h})$ & $0.77 \pm 0.03$ & $0.87 \pm 0.10$ & $0.93 \pm 0.08$ \\
\hline
\end{tabular}

Los rendimientos de biogás $(2.24 \mathrm{~L})$ por cada litro de vinaza de banano son proporcionales al biogás obtenido de vinaza de caña en donde para sólidos de $16.8 \%$ se obtienen como máximo $9 \mathrm{~L}$ de biogás (BNDES y CGEE, 2008).

\section{CONCLUSIONES}

La hidrólisis endógena y la extracción con cal, presenta grandes ventajas con respecto a las otras hidrólisis y extracciones evaluadas, porque este tipo de proceso puede ser utilizado a mayor escala por su bajo costo y viabilidad. La concentración promedio de alcohol alcanzada en los ensayos, permite concluir que los rendimientos son levemente más bajos que los obtenidos con caña de azúcar. El volumen de biogás obtenido a partir de las vinazas de banano es comparable e incluso proporcionalmente superior al obtenido a partir de las vinazas de caña de azúcar.

\section{AGRADECIMIENTOS}

Los autores agradecen a Colciencias, al Ministerio de Agricultura de Colombia y a la Universidad de Antioquia la financiación del presente trabajo.

\section{REFERENCIAS}

Afanador, A. M., El Banano Verde de Rechazo en la Producción de Alcohol Carburante, Revista Escuela de Ingenieria de Antioquia: 3, 1-18 ( 2005).

Asociación de Bananeros de Colombia. AUGURA, 2007. http://www.augura.com.co/Coyunturas/COYUNTURA\%20BANANERA\%202007.pdf. Acceso: 15 de Febrero (2010).

Augura y Fábrica de Licores de Antioquia (FLA), Estudio de Pre factibilidad Destilería de Alcohol de Banano. Informe institucional, 55-108. (1990)

Aurorea G., P. B., Fahrasmaneb L, Bananas, raw materials for making processed food products",Trends in Food Science \& Technology: 20, 78-91, (2009).

Banco de Desarrollo de Brasil (BNDES) y Centro de Gestión de Estudio Estratégico (CGEE), Bioetanol de caña de azúcar: energía para el desarrollo sostenible, $1^{a}$ edición, 55-120, Rio de Janeiro, Brasil, disponible en http://www.bioetanoldecanadeazucar.org . (2008)

Beckley, V. M., Paradi, C. A., Campanella, E. A. Comparación de secuencias de deshidratación de etanol por destilación extractiva con benceno. Información Tecnológica: 16 (5), 35-42 (2005). 
Canché-Escamilla. G., De los Santos-Hernández. J. M., Andrade-Canto. S., Gómez-Cruz R. Obtención de celulosa a partir de los desechos agrícolas del banano. Información Tecnológica: 16 (1), 83-88. (2005).

Davis. L., Jeon. Y., Svenson. C., Rogers. P., Pearce. J., Peiris. P. Evaluation of wheat stillage for ethanol production by recombinant Zymomonas mobilis. Biomass \& Bioenergy: 29, 49-59. (2005).

Hammond, J. Egg, R., Diggins, D., Coble C. G., Alcohol from bananas, Bioresource Technology: 56, 125-130. (1996).

Instituto Colombiano de Normas Técnicas y Certificación. 2009. Normas y publicaciones. http://www.icontec.org.co. Acceso: Octubre 10 (2010).

Kyamuhangire W., Myhre. H., Sørensen H., Pehrson R. Yield, Characteristics and Composition of Banana Juice Extracted by the Enzymatic and Mechanical Methods. J Sci Food Agric: 82, 478-482 (2002).

Kyamuhangire W., Pehrson. R. Conditions in Banana Ripening Using the Rack and Pit Traditional Methods and Their Effect on Juice Extraction. J Sci Food Agric: 79, 347-352 (1999).

Lee W.C, Yusof. S., Hamid N.S.A., Baharinn B.S. Optimizing Conditions for Hot Water Extraction of Banana Juice Using Response Surface Methodology (RSM). Journal of Food Engineering:75, 473-479 (2006).

Lee W.C., Yusof. S., Hamid N.S.A., Baharin B.S., Optimizing Conditions for Enzymatic Clarification of Banana Juice Using Response Surface Methodology (RSM). Journal of Food Engineering: 73, 55-63 (2006).

Margossian, L J., Ethylene-regulated Expression of a Tomato Fruit Ripening Gene Encoding a Proteinase Inhibitor I with a Glutamic Residue at the Reactive Site. Proc. Natl. Acad. Sci. USA: 85, 8012-8016 (1988).

Mojovic, L., Nikolic, S., Rakin, M., Vukasinovic. M. Production of bioethanol from corn meal hydrolyzates. Fuel: 85, 1750-1755 (2006).

Nigam, J. N., Ethanol production from wheat straw hemicelluloses hydrolysate by Pichia stipitis . Journal of biotechnology.: 87, 17-27. (2001).

O'Neal, C., Gas chromatographic procedures for determination of ethanol in postmortem blood using t-butanol and methyl ethyl ketone as internal standards. Forensic Science International: 83, 31-38 (1996)

Paull R., Heat Treatment and Fruit Ripening, Postharvest Biology and Technology: 21, 21-37. (2000).

Peláez, C., Mejía, A., Planas A. Development of a Solid Phase Kinetic Assay for Determination of Enzyme Activities During Composting. Process Biochemistry: 39 (8), 971-975 (2004).

Prabha T. N., Bhagyalakshmi N., Carbohydrate Metabolism in Ripening Banana Fruit. Phytochemistry: 48 (6), 915-919. (1998).

Rabelo. S. C., Carrere. H., Maciel Filho. R., Costa. A. C., Production of bioethanol, methane and heat from sugarcane bagasse in a biorefinery concept. Bioresource technology: 102, 7887-7895. (2011). 
Rodriguez-Porrata. B., Novo. M, Guillamón. J., Rozès. N., Mas. A., Cordero Otero. R. Vitality enhancement of the rehydrated active dry wine yeast. International Journal of Food Microbiology: 126 (1-2), 116-122. (2008).

Sierra, D. M. Informe en Comité Puebla-Panamá, Gobernación de Antioquia. Informe residuos en el proceso productivo de banano, 2007. http//www.augura.com.co. acceso: 10 de Octubre (2009).

Velásquez, H.I., Ruiz, A.A., De Oliveira S., Análisis energético y exergético del proceso de obtención de etanol a partir de la fruta del banano. Revista Facultad de Ingenieria Universidad de Antioquia: 51, 87-96 (2010). 